\title{
CORRECTIONS
}

\section{Ductal carcinoma in situ of the breast}

The authors of reference 34 in this Clinical Review by Nicola L P Barnes and colleagues (BMJ 2012;344:e797, doi:10.1136/ bmj.e797) have informed us that their quantitative study from 2010 is incorrectly referenced instead of their qualitative study from 2012. Reference 34 should be listed as Kennedy F, Harcourt D, Rumsey N. The shifting nature of women's experiences and perceptions of ductal carcinoma in situ. Journal of Advanced Nursing 2012;68:856-67.

Cite this as: BMJ 2012;344:e2113

๑ BMJ Publishing Group Ltd 2012 